\title{
Correlating the treatment outcome with tumor staging, grading, and various treatment modalities in patients with esthesioneuroblastoma
}

\author{
Shuchita Singh, Lavleen Singh', Richa Ranjan', Manoj Kumar Singh',Alok Thakar, Suresh Chandra Sharma
}

\begin{abstract}
Objective: Although till date no management protocol for esthesioneuroblastoma (ENB) has been standardized due to tumor rarity, still multimodality approach shows better treatment outcomes as compared to surgery alone.The objective of this study was to analyze the clinicopathological spectrum of ENB and to correlate treatment response with tumor staging, histopathological grading, and various treatment modalities. Materials and Methods: Twenty-one consecutive patients with biopsy-proven ENB were studied and evaluated for response to treatment in the form of complete tumor resolution. Results were analyzed and correlated with stage and grade of tumor and form of therapy received. Results: There was male preponderance (3.2:I) with age ranging between 7 and 63 years (median of 25 years). Survival rates significantly dropped with increasing tumor stage (63.6\% in stages A and B vs. $30 \%$ in stages $C$ and D) and grade ( $100 \%$ in Grades I and 2 vs. $31.25 \%$ in Grades 3 and 4 ). The recurrence rate was $80 \%$ in surgery alone group, which came down to $43.7 \%$ if surgery was supplemented with other modalities. In cases where multimodality treatment plan was used, endoscopic procedures fared equally as open surgical procedures. Conclusion: Hyam's grade and Kadish stage are important prognostic indicators of treatment outcome, with survival rates dropping with increasing tumor stage and grade. Multimodality treatment protocols have improved the disease outcome, making endoscopic surgery equivalent to radical surgeries regarding result outcomes and giving other advantages such as better cosmesis, less treatment-related morbidities, decreased hospital stay, and better cost-effectiveness.
\end{abstract}

Key words: Endoscopic excision, esthesioneuroblastoma, radiotherapy, surgery

\section{Introduction}

Esthesioneuroblastoma (ENB) is a malignant neuroectodermal tumor of the sinonasal tract $(6 \%$ of all sinonasal malignancies and $0.3 \%$ of upper aerodigestive tract cancers). Nearly 1500 cases have been reported in medical literature since its first description by Berger et al. in 1924. ${ }^{[1,2]}$ Their cell of origin is specialized sensory neuro-epithelial olfactory cells which can be histologically identified in the tumor. ${ }^{[3]}$ Owing to low tumor incidence, assembly of large case series or randomized trials is difficult, making standard management protocol determination challenging. The multi-modality approach has provided better survival than any of the modalities alone. ${ }^{[4]}$ In the single-modality approach, surgical intervention is reported to be superior over nonsurgical approaches with regard to better disease-free outcome and survival rates. ${ }^{[5]}$ In multi-modality approach, endoscopic surgery had better or equivalent survival rates as open surgery. In patients undergoing radical surgery, local recurrence was significantly higher if radiotherapy (RT) was not given ( 28 vs. $4 \%$ ). ${ }^{[6]}$ The objective of this paper was to study the clinicopathological spectrum of ENB and to correlate response to various treatment modalities with Modified Kadish stage and Hyam's grade.

\section{Materials and Methods}

This is a retrospective study of 21 consecutive patients of sinonasal ENB presenting to a tertiary care center, over a period of 4 years (2009-2013). Epidemiological parameters, clinical presentation, modified Kadish stage, Hyam's grade, and various treatment modalities adopted were studied and analyzed in each case with a follow-up of 6 months or more (mean 12 months). Sequential follow-up was done monthly during the $1^{\text {st }}$ year, 2 monthly in the $2^{\text {nd }}$ year, 3 monthly in the $3^{\text {rd }}$ year and 6 monthly thereafter, with clinical examination, nasal endoscopy, and radiology if

\begin{tabular}{|l|}
\hline Access this article online \\
\hline Quick Response Code: \\
\\
Website: www.sajc.org \\
\hline DOI: $10.4103 /$ sajc.sajc_273_18 \\
\hline
\end{tabular}

Departments of Otorhinolaryngology and 'Pathology, All India Institute of Medical Sciences, New Delhi, India Correspondence to: Dr. Shuchita Singh, E-mail:drshuch@yahoo.com and when required. Disease resolution meant the absence of clinical evidence of tumor during sequential follow-up for 6 months. Any evidence of disease before 6 months was considered as residual, whereas after 6 months was designated as recurrence. Response to treatment in the form of complete tumor resolution was correlated with the age of patient, stage, and grade of tumor and form of therapy received.

\section{Results}

There was male preponderance in our study (male-to-female ratio of 3.2:1). Age ranged from 7 to 63 years (median 25 years). Epistaxis was the most commont presentation (86\%) followed by nasal obstruction (81\%), anosmia (38\%), and visual complaints (38\%). Two patients had atypical presentation in the form of persistent hyponatremia with euvolemia (fulfilling the clinical criteria of the syndrome of inappropriate antidiuretic hormone secretion [SIADH]), which resolved after tumor resection, further consolidating the fact that these were paraneoplastic manifestation of ENB.

Majority of patients belonged to Kadish stage B (55\%$11 / 21$ patients) and stage $C(43 \%-9 / 21$ patients $)$, with just 1 patient in stage D and none in stage A. Histological Grade 4 (43\%-9/21 patients) and Grade $3(33 \%-7 / 21$ patients) were predominant histomorphological patterns seen in most of our patients, followed by Grade 2 and 1.

Of the total 21 patients, $55 \%$ (11 patients) underwent surgery followed by RT, $23.8 \%$ (5 patients) underwent surgery alone, whereas two patients each underwent surgery followed by chemo-radiation (CTRT) and neo-adjuvant chemotherapy (NACT) followed by surgery. One patient was treated with NACT followed by surgery and CTRT.

This is an open access journal, and articles are distributed under the terms of the Creative Commons Attribution-NonCommercial-ShareAlike 4.0 License, which allows others to remix, tweak, and build upon the work non-commercially, as long as appropriate credit is given and the new creations are licensed under the identical terms.

For reprints contact: reprints@medknow.com

How to cite this article: Singh S, Singh L, Ranjan R, Singh MK, Thakar A, Sharma SC. Correlating the treatment outcome with tumor staging, grading, and various treatment modalities in patients with esthesioneuroblastoma. South Asian J Cancer 2019;8:124-6. 
On sequential follow-up, 8 patients were alive with recurrence or residual disease. Three patients died due to progressive disease. Ten patients had complete treatment response with no clinical evidence of disease. Most of the patients with recurrence/residual disease had a higher Kadish Stage C/D (63.63\%), whereas most patients who did not reveal any evidence of recurrent/residual disease on regular follow-up were lower Kadish Stage B (70\%). Out of 10 patients belonging to Kadish Stage C/D, 70\% had recurrence, whereas only $36.36 \%$ of patients belonging to Stage B had recurrence. None of the patients with the recurrent/ residual disease had Hyams Grade 1 or 2; however, $50 \%$ of the patients showing no evidence of disease on regular follow up had Hyam's Grade 1/2. The survival rates significantly dropped with increasing tumor stage $(63.6 \%$ in Stages A and B vs. $30 \%$ in Stages $C$ and D) and tumor grade $(100 \%$ in Grades 1 and 2 vs. $31.25 \%$ in Grades 3 and 4 ).

Five out of total of 21 patients were treated with surgery alone. Only 1 patient was disease-free on follow-up and four patients had recurrence/residual disease $(80 \%)$, of which two expired due to progressive disease. Patients where multimodality treatment approach was used (16 patients), the recurrence/residual disease was found to be $43.7 \%$ (7 out of 16 patients). Open surgical procedures did not reveal any beneficial outcomes when compared to the endoscopic approach in the multimodality treatment plan. On the contrary, the endoscopic approach was found to be associated with a higher recurrence rate $(75 \%)$ if surgery alone was used.

\section{Discussion}

ENB, also known as olfactory neuroblastoma, is a rare malignant neuroendocrine neoplasm of neural crest origin, arising from olfactory epithelium with a bimodal presentation. In our study, the age ranged from 7 to 63 years with a median of 25 years. Majority of the patients presented with nasal obstruction and epistaxis, but unfortunately, neither of them can help to render a diagnosis. Anosmia was seen in $38 \%$ of patients, which can be a subtle indicator of olfactory region pathology. Two of our patients had manifestations of paraneoplastic SIADH, which has been reported to be associated with ENB,$^{[7-14]}$ which resolved after tumor resection indicating toward ectopic hormone secretion by the tumor.

Kadish stage and Hyam's grade are strong prognostic indicators as $63.63 \%$ of recurrences belonged to Kadish Stage C/D. Seventy percent of patients belonging to Kadish Stage C/D had recurrence, whereas only $36.36 \%$ of patients belonging to Stage B had recurrence. All recurrences belonged to Hyam's Grade 3 or $4 .{ }^{[3]}$

Another important prognostic factor is the involvement of cervical lymph nodes. In our study, locoregional metastasis in the form of positive cervical lymphadenopathy was seen in only 1 patient out of a total of $21(4.76 \%)$, who came back with recurrence within 4 months. Survival studies of ENB show the survival rate being $64 \%$ in patients without neck metastasis and $29 \%$ in patients with metastasis. ${ }^{[4]}$ Various studies report the incidence of locoregional metastasis to be between $10 \%$ and $44 \%,{ }^{[15-17]}$ however distant metastasis after primary tumor resection has been seen in $4 \%-8 \% .{ }^{[6]}$ Most commonly, the metastatic disease spreads to cervical lymph nodes, less frequent sites being lung and pleura, bone, brain, spinal cord, breast, and abdominal cavity. ${ }^{[18,19]}$ Metastasis to the brain and spinal cord is infrequent and usually identified only at post-mortem examination. ${ }^{[20]}$ In the spinal cord, $80 \%$ of metastasis is seen in cauda equine. ${ }^{[16]}$

Local tumor recurrence in our study was $52.3 \%$. Previous studies have reported recurrence rates ranging from $51 \%$ to $55 \%$, and the 5 -year survival rate of around $70 \% \cdot{ }^{[21]}$ Local recurrence has been reported even after 10 years of initial treatment, stressing on the importance of prolonged and regular follow-up, especially in young patients. ${ }^{[6]}$

Due to the paucity of clinical cases, a standard treatment protocol is still elusive. Various treatment modalities in vogue are surgery alone, ${ }^{[17-19]}$ radiation alone, ${ }^{[17,22-24]}$ neoadjuvant chemoradiation followed by surgery, ${ }^{[25,26]}$ surgery followed by $\mathrm{RT},{ }^{[27,28]}$ surgery followed by chemoradiation and chemoradiation alone. On comparing various treatment modalities, Dulguerov et al. in 2001 found the best outcome with the multi-modality approach (surgery plus radiation-65\% success, followed by chemo-radiation-51\%), as compared to single modality (surgery- $48 \%$ and radiation- $37 \%$ ). ${ }^{[4]}$ In our study also, the recurrence rate dropped from $80 \%$ (single modality) to $43.7 \%$ (multimodality). Surgical resection supplemented by other treatment modalities in the form of chemoradiation has been pivotal in providing better treatment response. In this study, due to a limited number of cases receiving neoadjuvant chemoradiation, the importance of this treatment modality could not be established confirmatively.

Traditional surgery for ENB had been craniofacial resection (enhanced exposure with the possibility of achieving gross total resection) as first described by Doyle and Paxton ${ }^{[29]}$ Stammberger et al. were the first to publish their experience with endoscopic treatment of nasal malignancies, including ENBs. ${ }^{[30]}$ For tumors belonging to Kadish Stage A and B, endoscopic resection is favored over open approach, ${ }^{[30,31]}$ as it does not compromise the radicality of resection. Endoscopic surgical approach when used in conjunction with other modalities is equivalent to craniofacial resection regarding result outcomes. In properly selected cases, trans-nasal endoscopic approach gives an added benefit of a desirable cosmetic outcome, less treatment-related morbidities and subsequently decreased hospital stay and faster recovery, thus better cost-effectiveness. ${ }^{[32]}$ In the present study, better treatment outcome with endoscopic approach can be partly attributed to the fact that majority of the endoscopically resected tumors belonged to Kadish Stage B. However taking Stage B as constant and comparing the outcomes of endoscopic versus open surgical procedures, no significant difference was noted $(66.67 \%$ vs. $60 \%)$.

\section{Conclusion}

Most of the clinical manifestations of ENB are vague; however, the presence of anosmia may be one of its subtle indicators. The clinician must be aware of rarer clinical manifestations of ENB in the form of paraneoplastic syndromes so that the optimal therapy can be timely delivered. Hyams grade and Kadish stage are important prognostic indicators. The patients presenting with locoregional or distant metastasis have a poorer prognosis. Multimodality treatment protocols have improved the response of treatment. The endoscopic surgery supplemented 
with other modalities is equivalent to radical surgeries regarding result outcomes and is superior with respect to better cosmesis, less treatment-related morbidities, decreased hospital stay and thus the better cost-effectiveness.

\section{Financial support and sponsorship}

Nil.

\section{Conflicts of interest}

There are no conflicts of interest.

\section{References}

1. Monteiro EM, Lopes MG, Santos ER, Diniz CV, Albuquerque AS, Monteiro AP, et al. Endoscopic treatment of esthesioneuroblastoma. Braz J Otorhinolaryngol 2011;77:171-7.

2. Berger L, Luc R, Richard D. L'esthesioneuroepitheliome olfactif. Bull Assoc Fr Etude Cancer 1924;13:410-21.

3. Thompson LD. Olfactory neuroblastoma. Head Neck Pathol 2009;3:252-9.

4. Dulguerov P, Allal AS, Calcaterra TC. Esthesioneuroblastoma: A meta-analysis and review. Lancet Oncol 2001;2:683-90.

5. Devaiah AK, Andreoli MT. Treatment of esthesioneuroblastoma: A 16-year meta-analysis of 361 patients. Laryngoscope 2009;119:1412-6.

6. Lund VJ, Howard D, Wei W, Spittle M. Olfactory neuroblastoma: Past, present, and future? Laryngoscope 2003;113:502-7.

7. Cullen MJ, Cusack DA, O'Briain DS, Devlin JB, Kehely A, Lyons TA, et al. Neurosecretion of arginine vasopressin by an olfactory neuroblastoma causing reversible syndrome of antidiuresis. Am J Med 1986;81:911-6.

8. Singh W, Ramage C, Best P, Angus B. Nasal neuroblastoma secreting vasopressin. A case report. Cancer 1980;45:961-6.

9. Maeda H, Tsuruya K, Yotsueda H, Taniguchi M, Tokumoto M, Hirakata H, et al. A case report of syndrome of inappropriate secretion of antidiuretic hormone with marked edema due to administration of hypertonic saline. Ther Apher Dial 2007;11:309-13.

10. Plasencia YL, Cortés MB, Arencibia DM, Dámaso TM, Contreras IL, Pino $\mathrm{AO}$, et al. Esthesioneuroblastoma recurrence presenting as a syndrome of inappropriate antidiuretic hormone secretion. Head Neck 2006;28:1142-6.

11. al Ahwal M, Jha N, Nabholtz JM, Hugh J, Birchall I, Nguyen GK, et al. Olfactory neuroblastoma: Report of a case associated with inappropriate antidiuretic hormone secretion. J Otolaryngol 1994;23:437-9.

12. Freeman SR, Mitra S, Malik TH, Flanagan P, Selby P. Expression of somatostatin receptors in arginine vasopressin hormone-secreting olfactory neuroblastoma - Report of two cases. Rhinology 2005;43:61-5.

13. Srigley JR, Dayal VS, Gregor RT, Love R, van Nostrand AW. Hyponatremia secondary to olfactory neuroblastoma. Arch Otolaryngol 1983; 109:559-62.

14. Osterman J, Calhoun A, Dunham M, Cullum UX Jr., Clark RM, Stewart DD, et al. Chronic syndrome of inappropriate antidiuretic hormone secretion and hypertension in a patient with olfactory neuroblastoma. Evidence of ectopic production of arginine vasopressin by the tumor. Arch Intern
Med 1986;146:1731-5

15. Rinaldo A, Ferlito A, Shaha AR, Wei WI, Lund VJ. Esthesioneuroblastoma and cervical lymph node metastases: Clinical and therapeutic implications. Acta Otolaryngol 2002;122:215-21.

16. Shaari CM, Catalano PJ, Sen C, Post K. Central nervous system metastases from esthesioneuroblastoma. Otolaryngol Head Neck Surg 1996;114:808-12.

17. Olsen KD, DeSanto LW. Olfactory neuroblastoma. Biologic and clinical behavior. Arch Otolaryngol 1983; 109:797-802.

18. Beitler JJ, Fass DE, Brenner HA, Huvos A, Harrison LB, Leibel SA, et al. Esthesioneuroblastoma: Is there a role for elective neck treatment? Head Neck 1991;13:321-6.

19. Djalilian M, Zujko RD, Weiland LH, Devine KD. Olfactory neuroblastoma. Surg Clin North Am 1977;57:751-62.

20. Becker LE, Hinton D. Primitive neuroectodermal tumors of the central nervous system. Hum Pathol 1983; 14:538-50.

21. Gore MR, Zanation AM. Salvage treatment of local recurrence in esthesioneuroblastoma: A Meta-analysis. Skull Base 2011;21:1-6.

22. Parsons JT, Mendenhall WM, Mancuso AA, Cassisi NJ, Million RR. Malignant tumors of the nasal cavity and ethmoid and sphenoid sinuses. Int J Radiat Oncol Biol Phys 1988;14:11-22.

23. Kadish S, Goodman M, Wang CC. Olfactory neuroblastoma. A clinical analysis of 17 cases. Cancer 1976;37:1571-6.

24. Elkon D, Hightower SI, Lim ML, Cantrell RW, Constable WC. Esthesioneuroblastoma. Cancer 1979;44:1087-94.

25. Simon JH, Zhen W, McCulloch TM, Hoffman HT, Paulino AC, Mayr NA, et al. Esthesioneuroblastoma: The university of lowa experience 1978-1998. Laryngoscope 2001;111:488-93.

26. Cantrell RW, Ghorayeb BY, Fitz-Hugh GS. Esthesioneuroblastoma: Diagnosis and treatment. Ann Otol Rhinol Laryngol 1977;86:760-5.

27. Skolnik EM, Massari FS, Tenta LT. Olfactory neuroepithelioma. Review of the world literature and presentation of two cases. Arch Otolaryngol 1966;84:644-53.

28. Oberman HA, Rice DH. Olfactory neuroblastomas: A clinicopathologic study. Cancer 1976;38:2494-502.

29. Doyle PJ, Paxton HD. Combined surgical approach to esthesioneuroepithelioma. Trans Am Acad Ophthalmol Otolaryngol 1971;75:526-31.

30. Stammberger H, Anderhuber W, Walch C, Papaefthymiou G. Possibilities and limitations of endoscopic management of nasal and paranasal sinus malignancies. Acta Otorhinolaryngol Belg 1999;53:199-205.

31. Suriano M, De Vincentiis M, Colli A, Benfari G, Mascelli A, Gallo A, et al. Endoscopic treatment of esthesioneuroblastoma: A minimally invasive approach combined with radiation therapy. Otolaryngol Head Neck Surg 2007; 136: 104-7.

32. Eloy JA, Vivero RJ, Hoang K, Civantos FJ, Weed DT, Morcos JJ, et al. Comparison of transnasal endoscopic and open craniofacial resection for malignant tumors of the anterior skull base. Laryngoscope 2009; 119:834-40. 